\title{
Geologia
}

\section{Proveniência e Idade do Metamorfismo das Rochas da Faixa Brasília, na Região de Tapira (SW de Minas Gerais)}

\author{
Carlos Humberto da Silva' (chsilva@ufmt.br), Luiz Sergio Amarante Simões², \\ Robert Krymsky ${ }^{3}$, Moacyr José Buenano Macambira ${ }^{3}$ \\ 'Departamento de Geologia Geral - Instituto de Ciências Exatas e da Terra - UFMT \\ Av. Fernando Corrêa s/n, CEP 78060-900, Cuiabá, MT, BRA \\ ${ }^{2}$ Departamento de Petrologia e Metalogenia - IGCE - UNESP, Rio Claro, SP, BRA \\ ${ }^{3}$ Laboratório de Geologia Isotópica - Centro de Geociências e Ciências Exatas - UFPA, Belém, PA, BRA \\ Recebido em 26 de outubro de 2005; aceito em 12 de julho de 2006
}

Palavras-chave: Grupo Canastra, Grupo Araxá, Sm/Nd.

\section{RESUMO}

A Faixa Brasília na região de Tapira, no SW do estado de Minas Gerais, exibe quatro domínios litotectônicos diferentes, imbricados através de falhas de empurrão, com vergência para o Cráton do São Francisco. Foram conduzidos estudos isotópicos através do método $\mathrm{Sm} / \mathrm{Nd}$, que revelam diferentes idades modelo e de metamorfismo para estas escamas. As rochas da escama inferior apresentam idade de metamorfismo de $543 \mathrm{Ma}$, enquanto a escama que a superpõem, apresentam idade de metamorfismo de 581 Ma. As idades modelo $\left(\mathrm{T}_{\mathrm{DM}}\right)$ são similares para as duas escamas, variando entre 1,7 e 2,2 Ga. Em função das características litológicas essas escamas são interpretadas como derivadas de rochas depositadas em plataforma continental distal, que tiveram como fonte principal rochas de idades paleoproterozóicas do Cráton do São Francisco. As rochas da escama superior apresentam idade de metamorfismo de 612 Ma e uma distribuição bimodal das idades modelo $\left(T_{D M}\right), 1,3$ e 1,9 - 2,0 Ga. Em função das características litológicas e isotópicas as rochas dessas escamas são interpretadas como depositadas em ambiente de talude continental ou assoalho oceânico, tendo os sedimentos fonte mista, de idades paleo- e mesoproterozóicas do Cráton do São Francisco. Embora, com as limitações impostas tanto pelo pequeno número de amostras analisadas, quanto pelas incertezas do método $\mathrm{Sm} / \mathrm{Nd}$, interpreta-se que o metamorfismo não foi síncrono nas diferentes escamas. Isto é esperado em um sistema de cavalgamento, no qual as escamas mais metamórficas justapõem-se às escamas menos metamórficas.

Keywords: Canastra Group, Araxá Group, Sm/Nd ages, Brasília Belt.

\begin{abstract}
The Brasília Fold Thrust Belt at Tapira area (SW of Minas Gerais State, Brazil) has four different litho-tectonic domains imbricated by thrust faults with vergency to the São Francisco Craton. Sm/Nd isotopic studies were undertaken and the results show different model and metamorphic ages for the thrust sheets. Rocks from the lower thrust sheet yield a metamorphic age of 543 Ma while the upper thrust sheet has a metamorphic age of $581 \mathrm{Ma}$. The TDM model ages are similar for both thrust sheets, between 1.7 and $2.2 \mathrm{Ga}$. Because of their lithologic characteristics, the thrust sheets are interpreted as having been deposited in a distal continental platform environment, their main source being Paleoproterozoic rocks of the São Francisco Craton. The upper thrust sheet rocks presents a metamorphism age of $612 \mathrm{Ma}$ and a bimodal distribution of TDM model ages between 1.3 and 1.9 - 2.0 Ga, respectively. The lithologic and isotopic characteristics of this thrust sheet the rocks are interpreted as a result of deposition on a continental slope or oceanic floor environment, with mixed contributions from Paleo - and Mesoproterozoic rocks of the São Francisco Craton. In spite of the small number of analyzed samples and the uncertainties inherent to the $\mathrm{Sm} / \mathrm{Nd}$ method the metamorphisms are not considered to be synchronous in the different thrust sheets. This is to be expected in a thrust belt system, in which the more metamorphosed thrust sheets are juxtaposed to less metamorphosed ones.
\end{abstract}




\section{INTRODUÇÃO}

Fracionamento importante da razão Sm/Nd, normalmente só ocorre nos eventos de diferenciação manto-crosta, por fusão parcial ou cristalização fracionada. Durante processos crustais, como fusão parcial, eventos metamórficos, diagênese e alterações hidrotermais, esta razão Sm/Nd tende a se manter constante, variando somente por decaimento radioativo (Sato et al., 1995; Arndt e Goldstein, 1987). Por isso pode-se datar a época em que o protólito crustal de uma dada rocha diferenciou-se do manto superior, independentemente dos processos geológicos posteriores. O cálculo dessa idade, conhecida como idade modelo, é feito através da determinação das razões ${ }^{147} \mathrm{Sm} /{ }^{144} \mathrm{Nd}$ e ${ }^{143} \mathrm{Nd} /{ }^{144} \mathrm{Nd}$ da amostra, a partir das quais calcula-se uma regressão até o intercepto com uma curva de evolução isotópica do Nd em função do tempo geológico (Sato et al., 1995).

Em rochas sedimentares e metassedimentares as idades modelo Sm/Nd correspondem a uma média ponderada das idades dos processos de diferenciação manto/crosta do material que deu origem às rochas fonte. Como a razão Sm/Nd é relativamente estável, estas idades têm sido amplamente utilizadas para avaliar as possíveis fontes de rochas detríticas de bacias sedimentares e cinturões metamórficos. Exemplos da utilização desta técnica são os estudos de Taylor e McLennan (1985), McLennan et al. (1995), Fetter (1999), Dantas (1996) e Costa (2002). Na Faixa Brasília esta técnica tem sido utilizada para separar e correlacionar as várias unidades litoestratigráficas da faixa, como por exemplo, Pimentel et al. (1998; 1999; 2001) e Seer (1999).

O presente trabalho tem por objetivo apresentar o padrão isotópico $\mathrm{Sm} / \mathrm{Nd}$ de 10 amostras de metassedimentos granatíferos de diferentes compartimentos lito-estruturais da Faixa Brasília na região de Tapira (SW do estado de Minas Gerais), interpretando o seu significado quanto à proveniência e idade de metamorfismo.

\section{SITUAÇÃO GEOLÓGICA}

A área estudada situa-se na Faixa Brasília, um orógeno colisional neoproterozóico, produto da interação de três blocos crustais representados pelos seus remanescentes atuais, os crátons Amazônico, São Francisco-Congo, e Paraná (Brito Neves e Cordani, 1991; Valeriano, 1999; Valeriano et al., 2004a; Figura 1). Este orógeno estende-se por mais de $1.000 \mathrm{~km}$ com direção aproximadamente N-S, bordejando a margem ocidental do Cráton do São Francisco. A área de estudo situa-se no segmento meridional da Faixa Brasília (Figura 2) onde a deformação e o metamorfismo, relacionados à orogênese neoproterozóica, foram intensos, contribuindo para obliteração das relações estratigráficas entre as várias unidades regionais.
As rochas estudadas apresentam uma complexa evolução estrutural com descontinuidades tectônicas de diferentes gerações, que justapõem terrenos de variadas origens e padrões metamórficos. A partir do reconhecimento das principais falhas regionais, Silva (2003) e Silva et al. (2004) propuseram uma compartimentação em três domínios tectonoestruturais, cujas principais características são sintetizadas nos parágrafos a seguir (ver também Figura 3).

No domínio oeste (DW) ocorrem duas escamas tectônicas separadas por falha de empurrão. Na escama 1 (Grupo Canastra) ocorrem granada-grafita-muscovita xistos com freqüentes intercalações de quartzitos. Na escama 2 (Grupo Araxá) ocorrem granada-mica xistos, com intercalações de hornblenda-mica xistos, anfibolitos e metaultramáficas, que passam gradativamente a quartzitos micáceos com intercalações de mica xistos, que, por sua vez, são sobrepostos por gnaisses. As associações minerais descritas para as rochas da escama 1 (granada-cloritóide-biotita-muscovita-clorita-quartzo) permitem situá-las na facies xisto verde superior. Já as rochas da escama 2 apresentam hornblenda e oligoclásio evidenciando condição de facies anfibolito.

No domínio leste (DE) foi definido um conjunto de três escamas com características litológicas distintas delimitadas por falhas de cavalgamento, que encontra-se empurrado sobre o Grupo Bambuí. A constituição litológica deste domínio é a seguinte:

1. Grupo Bambuí - marcado por filitos com lentes métricas de mármores calcíticos. As condições metamórficas das rochas deste grupo são de facies xisto verde inferior (zona da clorita).

2. Escama Inferior (Grupo Canastra) - apresenta na base quartzo-muscovita xistos intercalados por muscovita xistos, que em direção ao topo passam gradativamente a grafitamuscovita xistos. Estas rochas são sobrepostas por quartzomuscovita xistos, com intercalações de quartzitos. No topo desta escama ocorrem quartzitos puros a micáceos com intercalações de quartzo xistos. As associações minerais identificadas para estas rochas (clorita, muscovita, quartzo, biotita, cloritóide, albita) permitem considerá-las como na facies xisto verde inferior a médio (zonas da clorita e da biotita).

3. Escama Intermediária (Grupo Canastra) - granadagrafita-muscovita xistos de granulação fina intercalados a xistos grafitosos e granada-biotita-muscovita xistos, marcam a base desta escama. Estes são sobrepostos por granada-grafita xistos, que passam gradativamente a granadamica xistos pouco grafitosos. No topo desta escama ocorrem quartzitos com intercalações métricas de quartzo xistos, muscovita xistos e quartzitos micáceos. As associações minerais (granada, clorita, biotita, muscovita, quartzo, albita) presentes nas rochas desta escama indicam metamorfismo de facies xisto verde superior (zona da granada). 


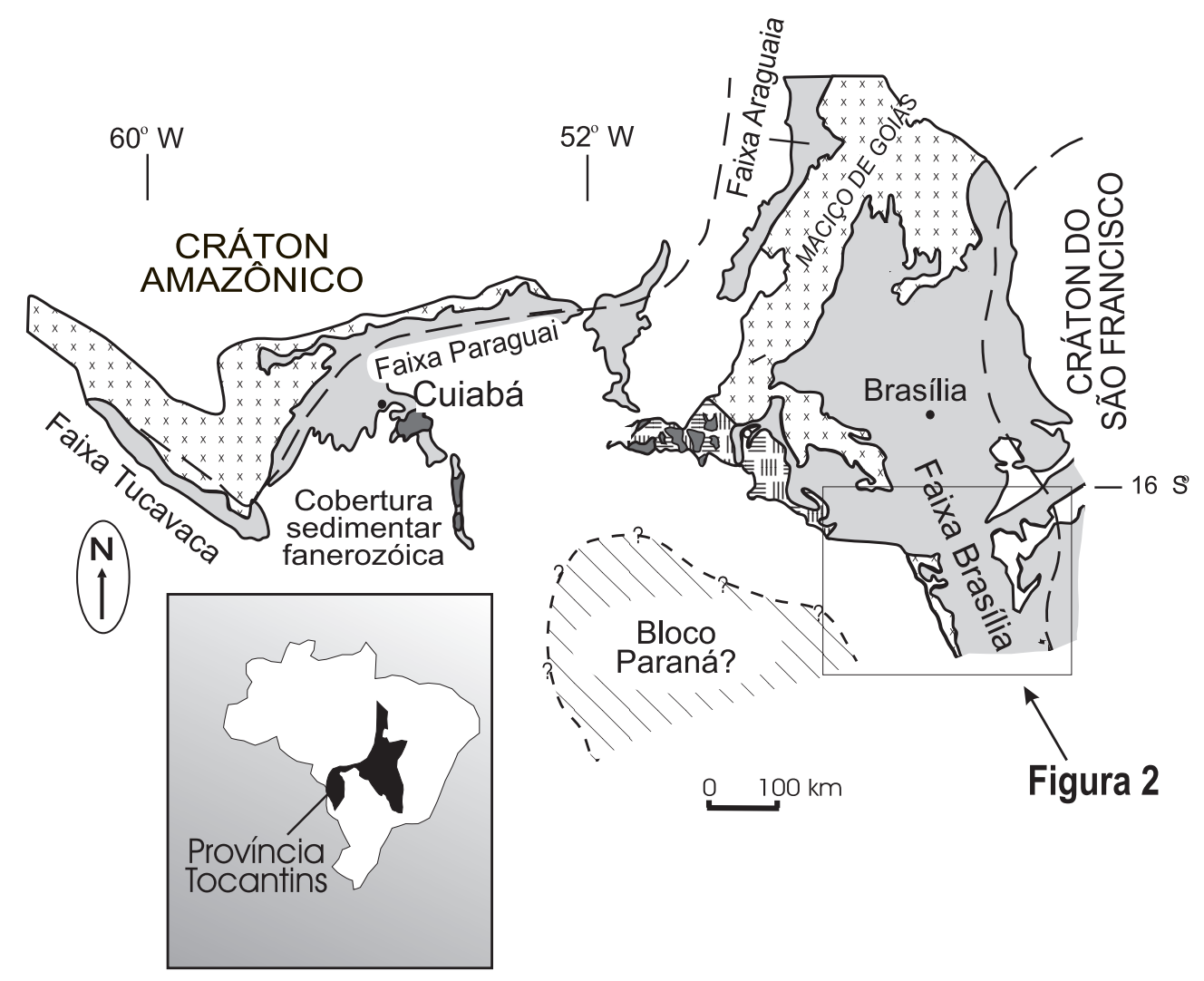

Figura 1. Situação da área estudada em relação à província Tocantins (segundo Fuck et al. 1993). O polígono delimita a área detalhada na Figura 2.

4. Escama Superior (Grupo Araxá) - o litotipo mais freqüente desta escama é granada-mica xistos, com camadas métricas de granada-quartzo xistos e rochas metaultramáficas. A assembléia metamórfica (granada, clorita, biotita, muscovita, quartzo, oligoclásio) das rochas desta escama remetem a metamorfismo de facies anfibolito inferior.

O empilhamento estratigráfico proposto para o domínio sul (DS) apresenta, na base, quartzo filitos que passam a metarenitos com intercalações de quartzo xisto. Em direção ao topo ocorre um pacote que alterna filito e metarenito. No topo da seqüência ocorrem metarenitos com lentes métricas de filitos e metaconglomerados. A associação mineral (clorita, muscovita e quartzo) presente nestas rochas e o baixo grau de recristalização, evidenciado pela preservação do contorno dos grãos sedimentares, revelam metamorfismo de facies xisto verde inferior (zona da clorita).

A princípio é possível a correlação das fases de deformação nos diferentes domínios, pois todos possuem uma foliação em baixo ângulo, em geral, a feição estrutural marcante em todos os afloramentos, à qual associa-se uma lineação de estiramento e/ou mineral. Estas estruturas são atribuídas à fase D4 que é a responsável pela foliação principal na área (S4), normalmente uma clivagem de crenulação, cuja superfície crenulada é uma foliação S2, subparalela ao acamamento sedimentar (S0). Em alguns locais S4 manifesta-se como uma xistosidade ou clivagem contínua. A foliação S4 também afeta dobras normais de escala quilométrica relacionadas à fase D3. Adicionalmente são reconhecidos dois conjuntos de dobras pós-fase principal com eixos de caimentos suaves e planos axiais íngremes, sendo os eixos de D5 de direção NW e os eixos de D6 de direção N-S. Relacionada à fase D5 associam-se três zonas de cisalhamento dúcteis/rúpteis de escala quilométrica, que marcam os limites entre os domínios definidos na área estudada.

O metamorfismo principal está relacionado a um estágio precoce da fase D2 conforme revelam estudos microestruturais (Silva, 2003; Silva e Simões, 2005). As falhas de empurrão, que justapõem as escamas tectônicas nos domínios leste e oeste, são relacionadas a um estágio tardio da fase D2. Estas falhas foram dobradas durante a fase D3. 


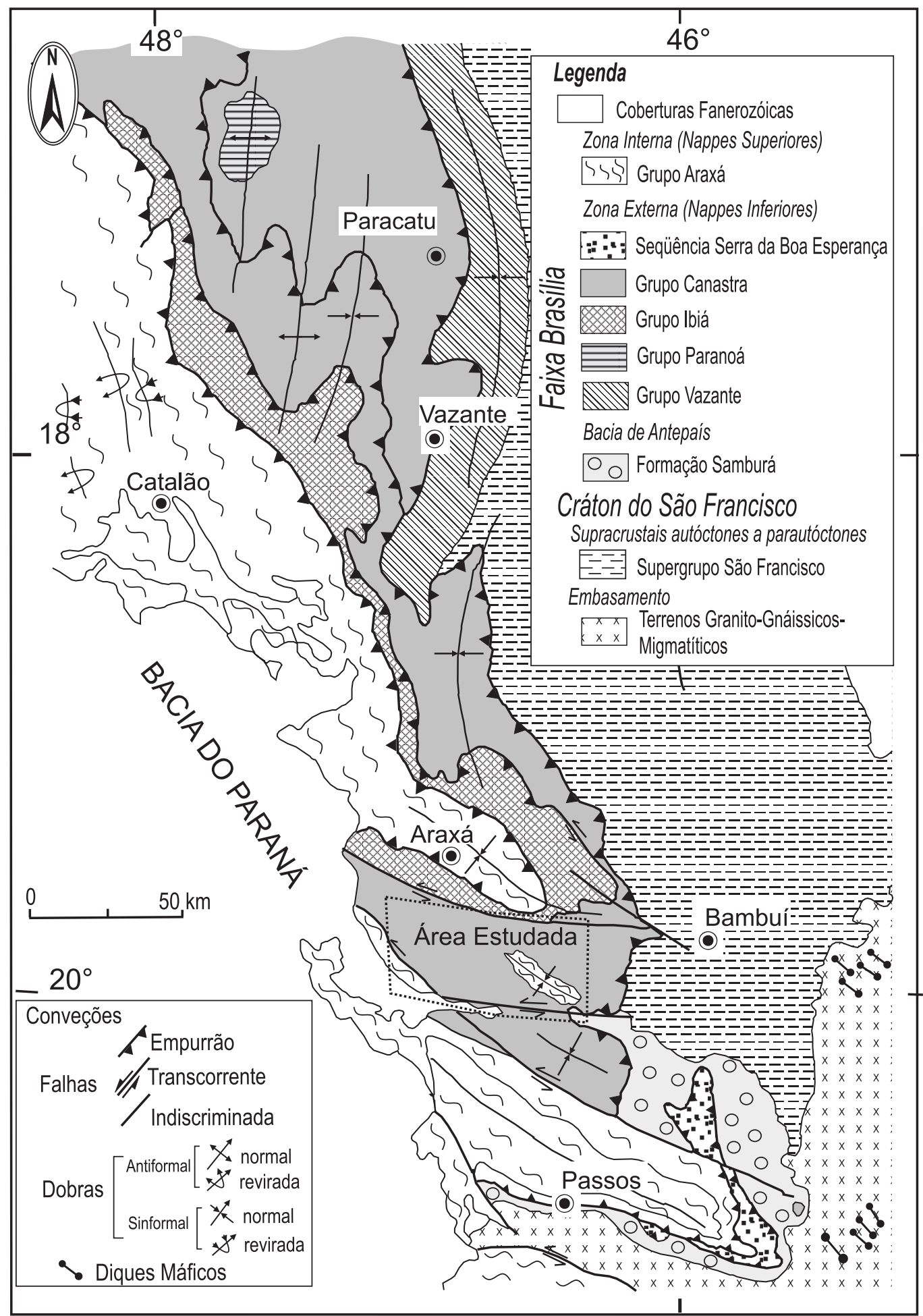

Figura 2. Esboço geológico da parte sul da Faixa Brasília (modificado de Valeriano, 1999). O polígono delimita a área estudada. 


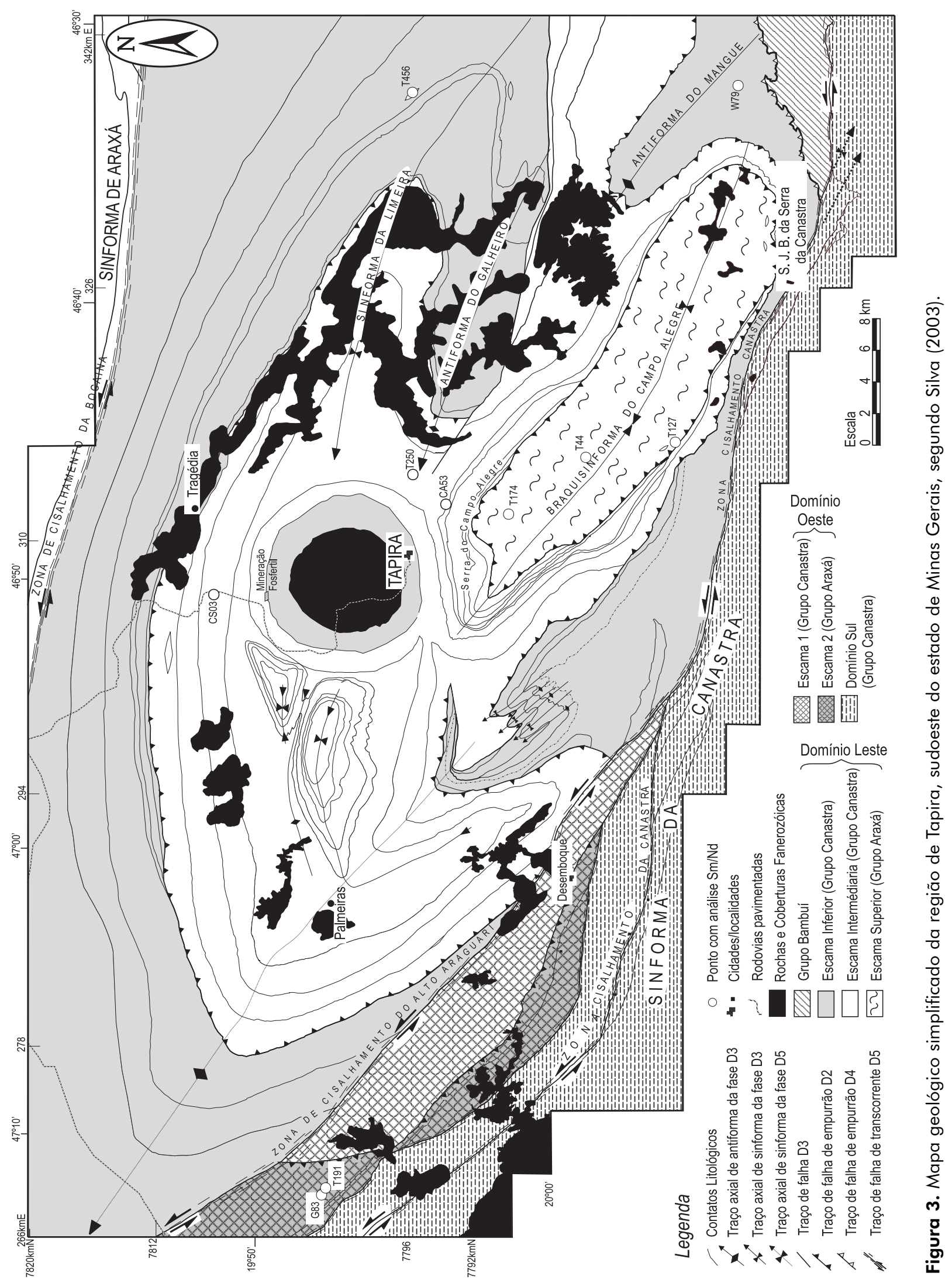




\section{DESCRIÇÃO DAS AMOSTRAS ESTUDADAS}

Para o estudo geocronológico $\mathrm{Sm} / \mathrm{Nd}$ foram selecionadas 10 amostras, cujas localizações são apresentadas no mapa geológico da Figura 3. Todas as amostras apresentam paragêneses minerais com granada. A Tabela 1 apresenta as principais características microscópicas das granadas, cujos concentrados foram analisados isotopicamente.

As granadas analisadas relacionam-se ao metamorfismo principal de cada domínio que, conforme indicam estudos microestuturais, ocorreu em estágio precoce do evento D2 (Silva, 2003; Silva e Simões, 2005). Esta fase também foi responsável pela imbricação das escamas tectônicas superior, intermediária e inferior no domínio leste e escamas 1 e 2 no domínio oeste.

Na Escama 2 (DW) foram selecionadas as amostras G83 e T191 que são de hornblenda-granada-mica xistos. Estas rochas ocorrem como lentes ou camadas com espessuras entre $10 \mathrm{~cm}$ e $5 \mathrm{~m}$, inclusas em granada-mica xistos. Este litotipo apresenta cor cinza escuro e aspecto homogêneo. Ao microscópio observa-se uma textura granolepidoblástica, com a seguinte mineralogia: quartzo, muscovita, granada, biotita, hornblenda, oligoclásio e clorita; como minerais acessórios ocorrem turmalina, epidoto, rutilo e opacos.

Da escama inferior (DE) foi selecionada uma amostra de quartzo-clorita-muscovita xisto (W79), que apresenta pequenos cristais de granada, rica em manganês. A rocha apresenta bandamento centimétrico marcado pela alternância de níveis quartzosos e micáceos. Em seções delgadas constitui-se por uma grande quantidade de micas que ultrapassam $65 \%$ do volume total da rocha, com predominância da muscovita sobre a clorita. Além desses minerais ocorrem também quartzo, albita, granada, biotita (rara), calcita, cloritóide, pirita, rutilo, zircão e turmalina.
Da porção média da escama intermediária (DE) foi selecionada a amostra CS3 que é de granada-grafita xisto. Este litotipo é cinza escuro quando fresco, ou cinza médio quando alterado. É comum a presença de veios, lentes e bolsões de caulim e quartzo. Em seção delgada constatou-se que o xisto possui textura granolepidoblástica porfirítica, com matriz composta por muscovita, quartzo, grafita, clorita, albita e biotita e porfiroblastos de cloritóide e granada. Como minerais acessórios ocorrem turmalina, rutilo e opacos.

Do topo da seqüência tectono-estratigráfica da escama intermediária (DE) foram selecionadas 2 amostras (CA53 e T250). Ambas são de granada-mica xisto, esverdeados, com intercalações milimétricas de camadas quartzosas e micáceas. Ao microscópio apresentam textura granolepidoblástica porfirítica com porfiroblastos de cloritóide, albita e granada, com matriz composta por quartzo, muscovita, biotita, grafita e opacos, além de turmalina e zircão como minerais acessórios. Também foi selecionada uma amostra de quartzito com granada (T456). Esta amostra apresenta textura granolepidoblástica porfirítica com matriz composta por quartzo, muscovita, biotita, albita e opacos, com porfiroblastos esqueletais de granada. Turmalina, zircão e opacos ocorrem como minerais acessórios.

As amostras T44, T127 e T174, são de granada mica xisto da escama superior (DE). Os afloramentos dessas rochas possuem cor esverdeada, sendo marcadas por um bandamento milimétrico de camadas micáceas e quartzosas, com a presença freqüente de veios de quartzo. Ao microscópio observa-se uma textura granolepidoblástica porfirítica, sendo distinguidos os seguintes minerais: quartzo, muscovita, biotita, granada, albita, clorita, opacos, além da turmalina, epidoto, zircão, carbonato e rutilo como minerais acessórios. As amostras T44 e T174 apresentam maior percentual de quartzo do que a amostra T127.

Tabela 1. Principais características microscópicas das granadas, cujos concentrados foram analisados isotopicamente.

\begin{tabular}{cccccc}
\hline Amostra & G83 & T174 & T250 & CS03 & W79 \\
\hline $\begin{array}{c}\text { Tamanho da } \\
\text { granada (mm) }\end{array}$ & 1 a 3 & 10 a 2 & 1 a 3 & 20 a 2 & 0,5 a 0,25 \\
\hline Munerais inclusos & $\begin{array}{c}\text { Quartzo, } \\
\text { plagioclásio, } \\
\text { epidoto, ilmenita, } \\
\text { turmalina }\end{array}$ & $\begin{array}{c}\text { Quartzo, } \\
\text { plagioclásio, } \\
\text { ilmenita }\end{array}$ & $\begin{array}{c}\text { Quartzo, } \\
\text { plagioclásio, } \\
\text { grafita, ilmenita, } \\
\text { epidoto }\end{array}$ & $\begin{array}{c}\text { Quartzo, } \\
\text { grafita, } \\
\text { ilmenita }\end{array}$ & $\begin{array}{c}\text { Quartzo, } \\
\text { ilmenita }\end{array}$ \\
\hline $\begin{array}{c}\text { Tamanho das } \\
\text { inclusões (mm) }\end{array}$ & 0,5 a 0,01 & 0,5 a 0,01 & 0,7 a 0,01 & 1 a 0,01 & $>0,01$ \\
\hline $\begin{array}{c}\text { Porcentagem de } \\
\text { inclusões em } \\
\text { relação a granada }\end{array}$ & 10 a 35 & 05 a 30 & 10 a 40 & 05 a 30 & 1 a 5 \\
\hline
\end{tabular}




\section{PROCEDIMENTOS ANALÍTICOS}

O procedimento adotado para a concentração de granadas das amostras CS03 e T174, que possuem grãos de tamanho centimétrico (ver Tabela 1), foi o seguinte:

a. retirada das granadas diretamente do afloramento utilizando martelo e cinzel;

b. cominuição das granadas em moinho de martelos;

c. peneiramento da amostra;

d. separação da fração compreendida entre 0,18 e 0,30 mm;

e. seleção manual dos grãos, mais puros e sem inclusão, utilizando lupa binocular.

Para as demais amostras (G83, T250 e W79) foi adotado o seguinte procedimento para preparação de concentrados de granada e plagioclásio:

a. cominuição da amostra em moinho de martelos;

b. peneiramento;

c. seleção do material com tamanho entre 0,18 e 0,30 mm;

d. bateamento;

e. seleção eletromagnética através de Franz;

f. seleção manual dos grãos, mais puros e sem inclusão, utilizando lupa binocular.

O peso dos concentrados de granada e plagioclásio enviados aos laboratórios foram de aproximadamente $80 \mathrm{mg}$.

Todas as amostras foram cominuídas em moinho de martelos e pulverizadas em moinho de bola a um tamanho inferior a 0,05 mm. Sendo em seguida separados $200 \mathrm{mg}$ da amostra que foi enviada aos laboratórios para o procedimento analítico.

Como as determinações Sm/Nd foram feitas em dois laboratórios (UFPA e UNB), a descrição sucinta da dissolução e concentração de amostras destes dois laboratórios é dada a seguir. No laboratório Pará-Iso (UFPA) a dissolução é feita pesando aproximadamente $50 \mathrm{mg}$ da mostra pulverizada e homogeneizada, e a mesma quantidade de traçador, em um cadinho de teflon de uma bomba de dissolução tipo PARR.

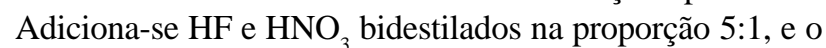
cadinho, devidamente tampado, é colocado no recipiente de metal da bomba e levado a estufa $\left(150^{\circ} \mathrm{C}\right)$ por sete dias. Após esse período ele é retirado da estufa e colocado para esfriar. O cadinho de teflon é levado à chapa aquecedora até a evaporação total da solução. Posteriormente é adicionado ao cadinho $\mathrm{HF}$ e $\mathrm{HNO}_{3}$ bidestilados e o cadinho, tampado, é colocado na chapa aquecedora durante aproximadamente 12 horas. Em seguida, o cadinho é destampado e a solução evaporada. Esse procedimento é repetido mais uma vez. Após isso, adiciona-se $\mathrm{HCl} 6 \mathrm{~N}$ e evapora-se e depois, $\mathrm{HCl} 2 \mathrm{~N}$ e evapora-se. Posteriormente, transfere-se a amostra para o tubo de centrifugação com $\mathrm{HCl} 2 \mathrm{~N}$, a qual é centrifugada por
20 minutos. A separação química do Sm e do Nd foi realizada em duas etapas. Na primeira etapa da separação cromatográfica, os elementos terras raras (ETR) são separados, a troca iônica é feita utilizando resina catiônica Dowex 50WX-8, que é colocada em colunas de teflon termo-retrátil de 5,0 mm de diâmetro. Na segunda fase, onde o Sm e o Nd são separados entre si dos demais ETR, a separação cromatográfica é feita utilizando a resina aniônica Dowex AG1-X4 que é colocada em coluna de teflon termo-retrátil com 5,0 mm de diâmetro. As soluções de Sm e Nd, coletadas em um bequer, são evaporadas e estão prontas para serem analisadas por espectrometria de massa. A análise isotópica é realizada em um espectrômetro de massa de termo-ionização FINNIGAN MAT 262 com 7 coletores. O Nd é depositado em um filamento de Ta e o Sm é depositado em um filamento de Re. A análise isotópica é feita utilizando um arranjo de filamento duplo constituído de um filamento de evaporação (filamento no qual o Sm ou Nd foi depositado) e um filamento de ionização. O filamento de ionização é aquecido para uma corrente de 4,5 ampéres (A) para provocar a ionização do metal (Sm ou $\mathrm{Nd}$ ) evaporado pelo aquecimento ( $\sim \mathrm{A})$ do filamento de evaporação. As razões isotópicas medidas do Nd foram corrigidas para o fracionamento de massa utilizando como parâmetro de normalização a razão ${ }^{146} \mathrm{Nd} /{ }^{144} \mathrm{Nd}=0,7219$.

No Laboratório de Geocronologia da UNB, a dissolução é realizada com aproximadamente 50 a 100 mg do pó das amostras de rocha. Estas são misturadas a uma solução traçadora mista de ${ }^{149} \mathrm{Sm} /{ }^{150} \mathrm{Nd}$ e em seguida digeridas (HF:HNO3 igual a aproximadamente 8:1) em cápsulas Savillex ou bombas de Teflon do tipo Parr ao longo de aproximadamente dois dias. Após essa primeira digestão, a solução é evaporada e novamente atacada com os mesmos ácidos por cerca de quatro dias. A solução é evaporada novamente e o resíduo solubilizado em $\mathrm{HCl} 6 \mathrm{~N}$ a quente. Após nova evaporação o resíduo é solubilizado em $\mathrm{HCl} 2,5 \mathrm{~N}$. A extração dos terras raras é feita pelos métodos convencionais em colunas de troca iônica confeccionadas em quartzo, usando resina BIO-RAD AG-50W-X8. A extração de Sm e de Nd foi feita em colunas em Teflon empacotadas com a resina LNSpec. As frações de Sm e Nd são depositadas em arranjos duplos de filamentos de rênio e analisadas na forma metálica, em modo estático, usando o espectrômetro de massa Finnigan MAT-262 multicoletor. A razão ${ }^{143} \mathrm{Nd} /{ }^{144} \mathrm{Nd}$ é normalizada a um valor de ${ }^{146} \mathrm{Nd} /{ }^{144} \mathrm{Nd}$ de 0,7219 e a constante de desintegração usada é 6,54 x 10-12 a-1. A precisão externa na determinação da razão ${ }^{143} \mathrm{Nd} /{ }^{144} \mathrm{Nd}$, baseada em repetidas análises do padrão BHVO-1, é melhor que \pm 20 ppm $(2 \sigma)$. Incertezas nas razões $\mathrm{Sm} / \mathrm{Nd}$ são melhores que $\pm 0,1 \%$.

O cálculo das idades foi realizado segundo o modelo do Manto Empobrecido de DePaolo (1981) e a constante de decaimento do ${ }^{147} \mathrm{Sm}$ utilizada foi a recomendada por Lugmair e Marti (1978). 


\section{RESULTADOS OBTIDOS}

Os resultados obtidos são apresentados na Tabela 2 . Os valores de $\mathrm{T}_{\mathrm{DM}}$ são representados como histogramas (Figura 4) e no diagrama de evolução de Nd (Figura 5).

\section{Estudo de Proveniência}

As amostras estudadas apresentam idades $\mathrm{T}_{\mathrm{DM}}$ entre 1,1 e 2,2 Ga, que podem ser divididas em dois grupos, o primeiro entre 1,1 e 1,3 Ga e o segundo entre 1,7 e 2,2 Ga.

O primeiro grupo compreende duas amostras da escama 2 (DW), com idades de 1,1 e 1,3 Ga, e uma das amostras da escama superior (DE) com $\mathrm{T}_{\mathrm{DM}} 1,3 \mathrm{Ga}$. Estas amostras apresentam $\mathcal{E}_{(0)}$ negativos, desde $-5,7$ a $-6,4$. Na escama superior (DE) também ocorrem rochas com $\mathrm{T}_{\mathrm{DM}}$ mais antigos de 1,9 e 2,0 $\mathrm{Ga}$, com $\mathcal{E}_{(0)}$ fortemente negativos de $-14,8$ e -17,6. Interpreta-se que estas rochas foram originadas a partir de áreas fonte com diferentes tempos de extração do manto. Outro processo que possivelmente influenciou nos padrões $\mathrm{T}_{\mathrm{DM}}$ é o tipo de sedimentação. As amostras com $\mathrm{T}_{\mathrm{DM}}$ entre 1,1 e 1,3 são granada-mica xistos provenientes do metamorfismo de folhelhos e argilitos, originados a partir de deposição pelágica. Já as rochas com $\mathrm{T}_{\mathrm{DM}}$ entre 1,9 e 2,0 Ga são quartzo-granadamica xistos cujos protólitos eram siltitos ou arenitos finos, depositados em ambiente profundo por fluxo gravitacional.

Embora a idade de deposição das rochas do primeiro grupo de amostras não tenha sido obtida, as idades modelo estabelecem um limite de 1,1 - 1,3 Ga como a idade máxima para sedimentação dos protólitos das rochas das escamas 2 (DW) e Superior (DE).

O segundo grupo de idades refere-se às amostras das escamas intermediária e inferior do domínio leste, que apresentam $\mathrm{T}_{\mathrm{DM}}$ entre 1,7 e $2,2 \mathrm{Ga}$, com os valores de $\boldsymbol{E}_{\mathrm{Nd}}$ fortemente negativos entre $-14,5$ e $-19,8$.

Considerando-se que o período de acreção magmática identificado para a Faixa Brasília situa-se principalmente entre 0,6 e 0,9 Ga (Pimentel e Fuck, 1992) os valores de $\varepsilon_{\mathrm{Nd}}$ para as amostras com $\mathrm{T}_{\mathrm{DM}}$ entre 1,1 e 1,3 Ga, calculados para o período neoproterozóico citado acima, fornece valores positivos entre $+0,7$ e $+1,1$, o que sugere que a fonte para metassedimentos pode ter incluído rochas juvenis neoproterozóicas.

Tabela 2. Resultados das determinações $\mathrm{Sm} / \mathrm{Nd} .{ }^{*}$ - amostras obtidas no Laboratório de Geocronologia do IGC/UNB. \# - amostras obtidas no Laboratório de Geologia Isotópica do CG/UFPA. $\mathbf{R T}=$ rocha total. $\mathbf{G R}=$ granada. $\mathbf{F E L}=$ feldspato.

\begin{tabular}{|c|c|c|c|c|c|c|c|c|}
\hline \multirow{2}{*}{$\begin{array}{c}\text { Amostra } \\
\text { Escama } 1\end{array}$} & \multirow[t]{2}{*}{ Mat. } & \multirow[t]{2}{*}{$\begin{array}{c}\mathrm{Sm} \\
(\mathrm{ppm})\end{array}$} & \multirow[t]{2}{*}{$\begin{array}{c}\mathrm{Nd} \\
(\mathrm{ppm})\end{array}$} & \multirow[t]{2}{*}{${ }^{147} \mathrm{Sm} /{ }^{144} \mathrm{Nd}$} & \multicolumn{2}{|c|}{$\begin{array}{c}{ }^{143} \mathrm{Nd} / /^{144} \mathrm{Nd} \\
( \pm 1 \sigma)\end{array}$} & \multirow[t]{2}{*}{$\varepsilon_{(0)}$} & \multirow[t]{2}{*}{$\begin{array}{l}\mathrm{T}_{\mathrm{DM}} \\
(\mathrm{Ga}) \\
\end{array}$} \\
\hline & & & & & & & & \\
\hline T191* & RT & 5,74 & 26,572 & 0,13060 & 0,512344 & $(11)$ & $-5,7$ & 1,3 \\
\hline G83 ${ }^{\#}$ & RT & 10,18 & 52,35 & 0,11759 & 0,512322 & (10) & $-6,2$ & 1,1 \\
\hline${\mathrm{G} 83^{\#}}^{\#}$ & GR & 3,35 & 10,99 & 0,18406 & 0,512436 & (20) & & \\
\hline \multicolumn{9}{|c|}{ Escama Superior (Domínio Leste) } \\
\hline $\mathrm{T} 127^{\star}$ & $\mathrm{RT}$ & 5,183 & 24,586 & 0,12740 & 0,512312 & (23) & $-6,4$ & 1,3 \\
\hline T44* & RT & 6,731 & 33,82 & 0,12030 & 0,511878 & (21) & $-14,8$ & 1,9 \\
\hline $\mathrm{T} 174^{\#}$ & RT & 8,67 & 45,72 & 0,11467 & 0,511735 & (08) & $-17,6$ & 2,0 \\
\hline $\mathrm{T} 174^{\#}$ & GR & 2,33 & 4,53 & 0,31129 & 0,512524 & $(12)$ & & \\
\hline \multicolumn{9}{|c|}{ Escama Intermediária (Domínio Leste) } \\
\hline T456* & $\mathrm{RT}$ & 3,66 & 17,92 & 0,12340 & 0,511722 & (29) & $-17,9$ & 2,2 \\
\hline CA53* & RT & 10,437 & 53,49 & 0,11800 & 0,511818 & (16) & $-16,0$ & 1,9 \\
\hline $\mathrm{T} 250^{\#}$ & RT & 8,62 & 46,65 & 0,11173 & 0,511897 & (10) & $-14,5$ & 1,7 \\
\hline $\mathrm{T} 250^{\#}$ & GR & 3,26 & 7,04 & 0,28035 & 0,512452 & (08) & & \\
\hline $\mathrm{T} 250^{\#}$ & FEL & 4,77 & 26,02 & 0,11095 & 0,511863 & (10) & & \\
\hline $\mathrm{CSO}^{\#}$ & $\mathrm{RT}$ & 7,09 & 37,62 & 0,11397 & 0,511623 & (10) & $-19,8$ & 2,2 \\
\hline $\mathrm{CSO}^{\#}$ & GR & 0,91 & 1,85 & 0,29630 & 0,512317 & (28) & & \\
\hline \multicolumn{9}{|c|}{ Escama Inferior (Domínio Leste) } \\
\hline W79"\# & $\mathrm{RT}$ & 10,9 & 56,94 & 0,11574 & 0,511839 & $(12)$ & $-15,6$ & 1,9 \\
\hline W79 ${ }^{\#}$ & GR & 3,83 & 12,26 & 0,18878 & 0,512099 & (18) & & \\
\hline
\end{tabular}




\section{Idades do Metamorfismo}

Foram feitas determinações Sm/Nd em concentrados de granada de cinco amostras e em uma amostra, também foi analisado concentrado de feldspato. Com essas análises, construiu-se diagramas isocrônicos, a partir dos quais foram determinadas as idades do metamorfismo principal nas várias escamas.

Na escama superior a amostra T174 apresenta idade de metamorfismo de $612 \pm 6$ Ma (Figura 6). Para a escama intermediária (amostra CS03) obteve-se como idade de metamorfismo $581 \pm 12 \mathrm{Ma}$ (Figura 7A). Para a escama inferior a idade do metamorfismo foi calculada a partir de dados da amostra W79, fornecendo valores de $543 \pm 22 \mathrm{Ma}$ (Figura 7B).

As amostras G83 (escama 2 [DW]) e T250 (escama intermediária [DE]), apresentam idades de metamorfismo muito menores que as determinadas para as demais amostras e fora dos padrões esperados para a Faixa Brasília $(\mathrm{G} 83=262 \mathrm{Ma} \mathrm{e} \mathrm{T250} \mathrm{=} 502 \mathrm{Ma})$.

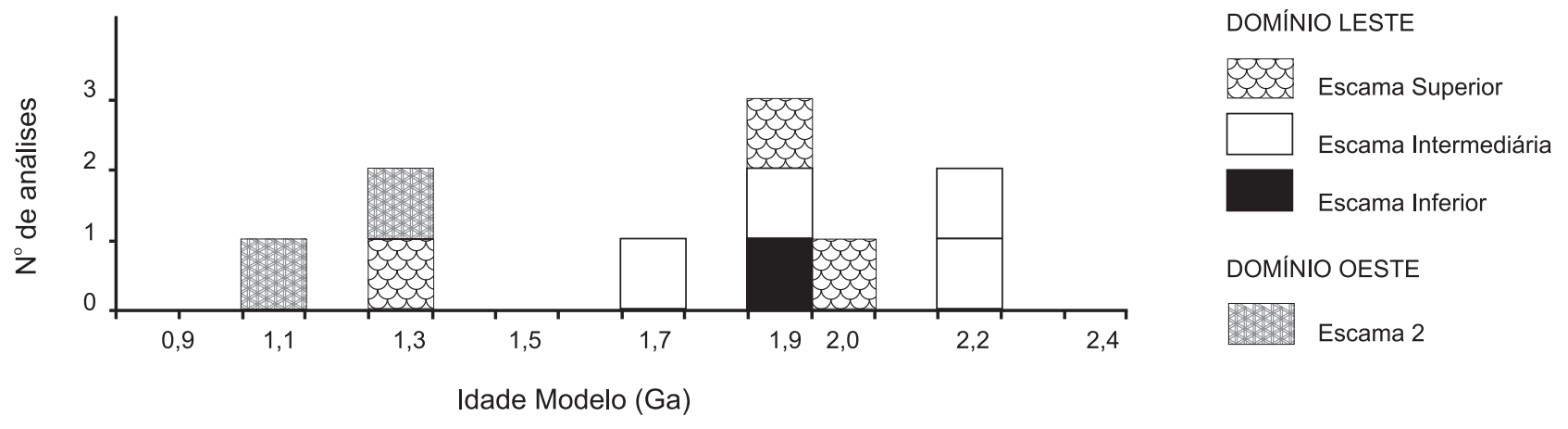

Figura 4. Histograma para os valores de idade modelo $\mathrm{Sm} / \mathrm{Nd}$ (manto empobrecido) das amostras da região de Tapira (MG).

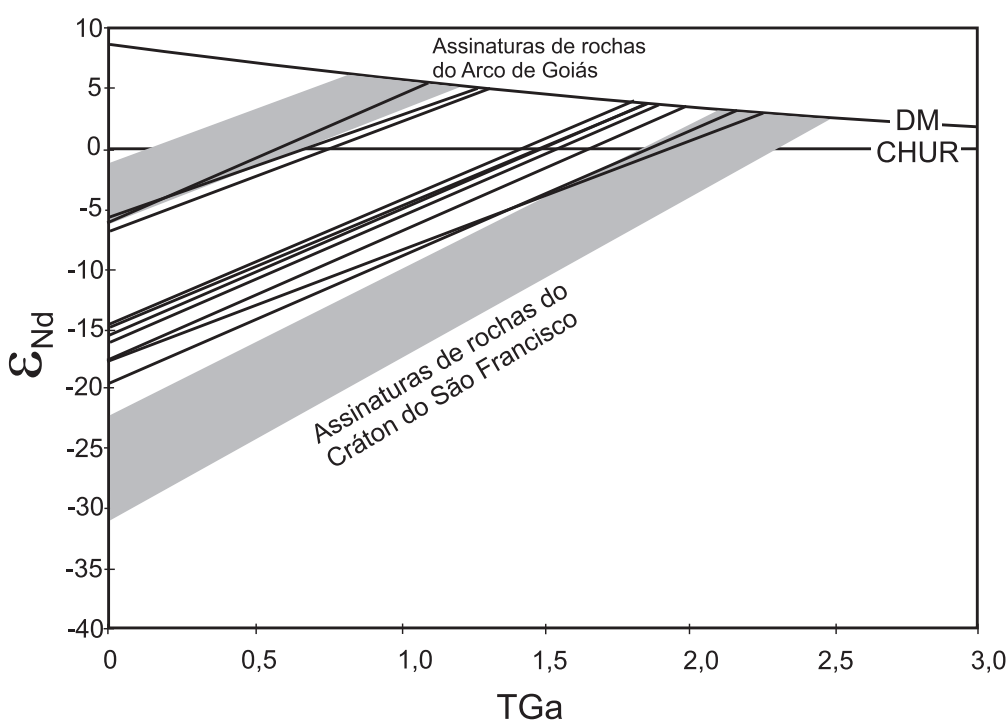

Figura 5. Características isotópicas de $\mathrm{Nd}$ das amostras da região de Tapira. Para comparação também foram inseridos os campos composicionais definidos pelas rochas do Arco Magmático de Goiás e das rochas do Cráton do São Francisco. 


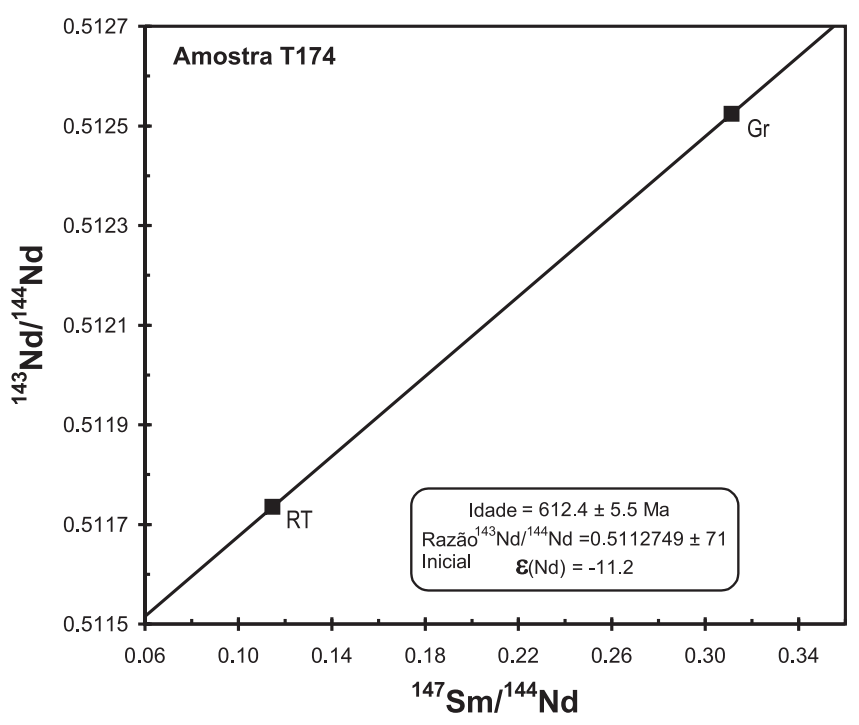

Figura 6. Diagrama isocrônico $\mathrm{Sm} / \mathrm{Nd}$ para rocha total (RT) e granada (GR) da amostra T174 situada na escama superior (DE).

(A)

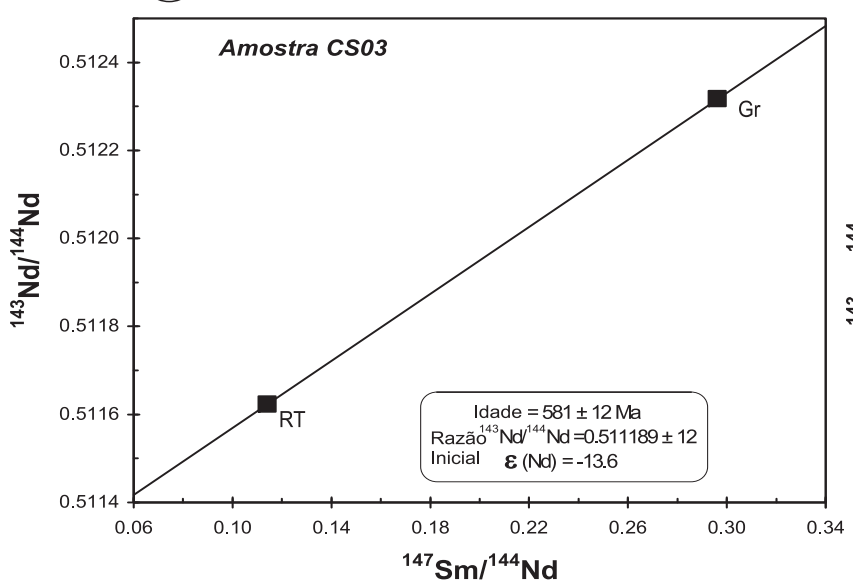

(B)

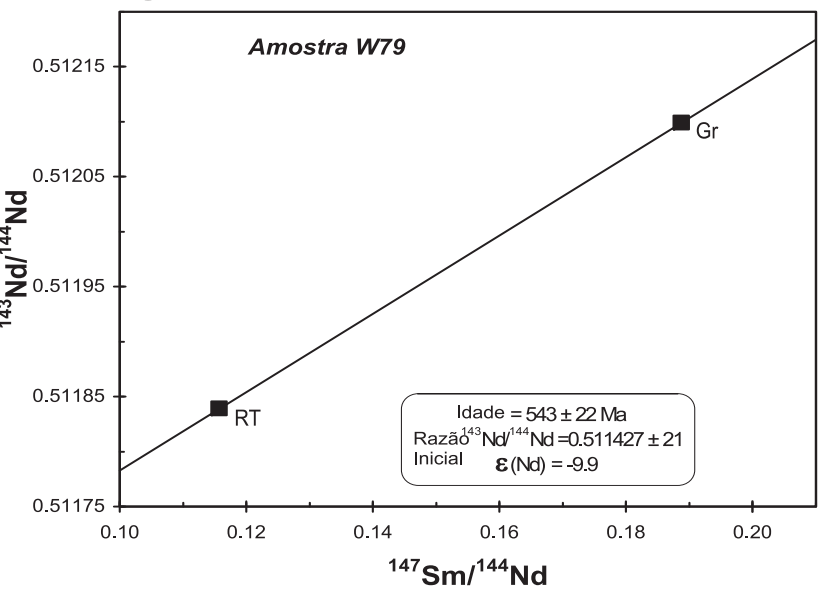

Figura 7. Diagramas isocrônicos $\mathrm{Sm} / \mathrm{Nd}$ para rocha total (RT) e granada (GR), das amostras CS03 ([A] escama intermediária, $D E)$ e W79 ([B] escama inferior $D E$ ). 


\section{DISCUSSÃO E CONCLUSÕES}

\section{Estudo de Proveniência}

O mapeamento geológico da região de Tapira (Silva, 2003) revelou que as rochas desta região foram depositadas em uma margem continental passiva e que as rochas das diferentes escamas identificadas representam diferentes facies sedimentares dessa margem. As rochas das escamas inferior e intermediária (DE) são interpretadas como representantes de facies de plataforma distal, sendo correlacionadas ao Grupo Canastra. Os dados $\mathrm{Sm} / \mathrm{Nd}$ de amostras dessas escamas apresentam $\mathrm{T}_{\mathrm{DM}}$ entre 1,7 e 2,2 Ga, $\boldsymbol{\varepsilon}_{\mathrm{Nd}(0)}$ fortemente negativos (-14,5 e -19,8), permitindo que as considere como originadas a partir de uma fonte crustal antiga retrabalhada. A distribuição espacial das litologias sugere que esta plataforma tenha se desenvolvido às margens de um paleocontinente, cujos remanescentes compõem a infraestrutura do Cráton do São Francisco. Desta forma interpreta-se que a principal fonte para estes metassedimentos foram as rochas paleoproterozóicas do Cráton do São Francisco (Cinturão Mineiro, Cordani e Sato, 1999). Esta conclusão é semelhante à de Pimentel et al. (2001) que analisaram assinaturas isotópicas de sedimentos finos dos grupos Arai, Paranoá, Serra da Mesa, Araxá, Ibiá, Vazante, Canastra e Bambuí, com o objetivo de investigar, a idade de residência crustal média das áreas fonte e o significado geotectônico das diferentes unidades da Faixa Brasília. Este estudo mostrou que as idades modelo $\mathrm{T}_{\mathrm{DM}}$ para as rochas dos grupos Paranoá, Vazante e Canastra variam no intervalo entre 1,7 e 2,3 Ga, e sugerem que estas foram formadas a partir da erosão de rochas com fontes crustais paleoproterozóicas do Cráton do São Francisco.

As características litológicas e a associação faciológica (para maiores detalhes ver Silva, 2003) evidenciam que, as rochas da escama superior (DE) e da escama 2 (DW) devem representar depósitos em talude continental ou assoalho oceânico, sendo correlacionadas ao Grupo Araxá. As rochas da escama superior apresentam uma distribuição bimodal de idades modelo (1,1 - 1,3 e 1,9 - 2,0 Ga). Embora para a escama 2 (DW) os valores $\mathrm{T}_{\mathrm{DM}}$ encontrados tenham sido 1,1 e 1,3 Ga, é possível e provável, que com um maior número de amostras, sejam identificadas $\mathrm{T}_{\mathrm{DM}}$ paleoproterozóicas. Este padrão é comum às rochas do Grupo Araxá, e vem sendo descrito em várias regiões da Faixa Brasília (Pimentel et al., 2001). Duas são as hipóteses propostas para explicar o padrão bimodal presente nestas amostras.

A primeira hipótese defendida por Pimentel et al. (1998, 1999, 2001) é que estas rochas seriam originadas a partir de uma mistura de rochas fonte com idades $\mathrm{T}_{\mathrm{DM}}$ paleoproterozóicas e neoproterozóicas. Neste caso, as prováveis fontes seriam as rochas do Cráton do São Francisco, que apresentam idades modelo predominantemente paleoproterozóicas (Cordani e Sato, 1999), e as rochas juvenis de arcos magmáticos similares ao Arco Magmático de Goiás, cujas idades variam entre 640 e 900 Ma (Pimentel e Fuck, 1992). Neste sentido a diferença entre os valores $\mathrm{T}_{\mathrm{DM}}$ paleoproterozóicos e mesoproterozóicos deve-se a uma maior influência de uma área fonte ou de outra, durante a deposição das rochas. A adoção desta hipótese implica que grande parte das rochas do Grupo Araxá tenha sido depositada em uma bacia de back-arc, o que significa que ao mesmo tempo em que as rochas do Grupo Araxá estavam sendo depositadas já havia se instalado uma zona de subducção com formação de arcos magmáticos.

A segunda hipótese propõe que as rochas com $\mathrm{T}_{\mathrm{DM}}$ de 1,1 - 1,3 Ga originaram-se a partir da erosão de rochas com idade Mesoprotezóica. Esta proposta é mais simples, pois, não exige uma mistura de fontes. Porém, é dificultada pela ausência de rochas com idade mesoproterozóicas aflorando tanto no Cráton do São Francisco, quanto no embasamento da Faixa Brasília. No entanto, estudos conduzidos por Valeriano et al. (2004a) descrevem a ocorrência de zircões detríticos, com idades entre 0,9 - 1,3 Ga, associados às seqüências quartzíticas, tipicamente plataformais, dos Grupos Araxá e Canastra na região de Passos, Araxá e Andrelândia. Estes autores associam os zircões a um magmatismo anorogênico, associado à abertura de rifts. Interpretam que os afloramentos destas rochas não são visíveis porque estariam recobertos pelo Grupo Bambuí ou pelo sistema de nappes do domínio externo. De maneira similar a primeira proposta, esta hipótese supõe que as rochas com idade modelo mais antiga (1,9 - 2,0 Ga) seriam originadas a partir da erosão das rochas do Cráton do São Francisco, que apresentam idades modelo predominantemente paleoproterozóicas (Cordani e Sato, 1999). Dessa forma, esta hipótese propõe que toda a sedimentação seja proveniente do paleocontinente são franciscano, contrapondo-se à primeira hipótese que supõe que parte da sedimentação é oriunda de arcos magmáticos intraoceânicos.

Considera-se a segunda hipótese como a mais adequada para explicar o padrão bimodal das rochas do Grupo Araxá na região. Esta conclusão advém do fato das rochas da escama superior (DE) e da escama 2 (DW) serem interpretadas por Silva (2003) e Silva et al. (2004), com base em características litológicas e faciológicas, como representantes de um talude continental desenvolvido na plataforma continental passiva do paleocontinente são franciscano. Portanto, depositadas sob forte influência de um aporte sedimentar proveniente do paleocontinente são franciscano, e com pouca influência de rochas do arco. 


\section{Idade de Metamorfismo}

Durante os últimos 15 anos vem crescendo a utilização do método $\mathrm{Sm} / \mathrm{Nd}$ aplicado ao par granada-rocha total para datação de eventos metamórficos (Thöni, 2003). Isto se deve à possibilidade de extrair informações microestruturais e termobarométricas e combiná-las às datações para reconstruções de tempo mais precisas. Outros minerais como zircão, monazita (método U/Pb) e hornblenda (método $\mathrm{Ar} / \mathrm{Ar}$ ), também são utilizados com a mesma finalidade, porém, estes minerais freqüentemente são de difícil compreensão no contexto da evolução PTd (Pressão-Temperatura-deformação) de terrenos metamórficos.

Embora o método $\mathrm{Sm} / \mathrm{Nd}$ aplicado à granada tenha se mostrado uma ferramenta extremamente útil na datação de eventos em terrenos metamórficos (como por exemplo, Vance e Harris, 1999; Argles et al., 1999), a interpretação dessas idades, nem sempre é simples. Trabalhos recentes (Burton et al., 1995; Chavagnac e Jahn, 1996; Thöni, 2003) mostram a influência de três problemas principais:

a. presença de inclusões ricas em terras raras leves;

b. desequilíbrio isotópico, entre a granada e os minerais de matriz, assim como a granada e as inclusões;

c. a incerteza sobre temperatura de fechamento (Tc) da granada, que varia de $\sim 600^{\circ} \mathrm{C}$, conforme sugerido por Humphries e Cliff (1982) e Mezger et al. (1992), a temperaturas superiores a $750^{\circ} \mathrm{C}$ (Thöni e Jagoutz, 1992; Chavagnac e Jahn, 1996).

A aplicação do método $\mathrm{Sm} / \mathrm{Nd}$ em granadas das rochas da Faixa Brasília na região de Tapira mostra que as idades de metamorfismo registram diferenças entre as escamas. $\mathrm{Na}$ escama superior a idade é de $612 \pm 6$ Ma. Esta idade é concordante com outras idades de metamorfismo estimadas para a Faixa Brasília principalmente as do Grupo Araxá, como por exemplo, a isócrona calculada por Seer et al. (2001) na área tipo do grupo na região de Araxá, que definiu a idade do metamorfismo em $637 \pm 12$ Ma. Na região centro-sul de Goiás, Fishel et al. (1998) apresentam idades de $600 \pm 30$ Ma para o metamorfismo de alto grau associados às rochas do Complexo Anápolis-Itauçu. Mais ao norte, na região de Mara Rosa, Pimentel et al. (1998) identificaram, pelo método $\mathrm{Sm} / \mathrm{Nd}$, duas idades de metamorfismo relacionadas às rochas supracrustais, associadas ao Arco de Mara Rosa, o primeiro em 780 - 790 Ma e um segundo em 610 Ma.

Para a escama intermediária a idade é de $581 \pm 12$ Ma e para a escama inferior a idade registrada é de $543 \pm 22$ Ma. Não foram identificadas na literatura consultada, idades do metamorfismo obtidas pelo método $\mathrm{Sm} / \mathrm{Nd}$, para as rochas do Grupo Canastra ou unidades correlatas. No entanto, Valeriano (1992) e Valeriano et al. (2000) apresentam idades
K/Ar representativas da idade do resfriamento do metamorfismo nas rochas do Grupo Canastra, da região de Ilicínea, na zona frontal da Nappe de Passos. Nesta região foram identificadas idades entre 588 e $567 \mathrm{Ma}$. Uma idade similar de 579 \pm 53 Ma foi obtida por Hasui e Almeida (1970), pelo método $\mathrm{K} / \mathrm{Ar}$, em uma amostra de filito coletado nas proximidades do Ribeirão da Prata (oeste da área). Esta idade é relacionada, pelos autores, ao resfriamento da rocha.

Uma possibilidade plausível de interpretação destes dados é a de que o metamorfismo não foi síncrono nas diferentes escamas, o que é esperado para um sistema de cavalgamento justapondo níveis mais metamórficos sobre níveis menos metamórficos. Como o número de amostras analisadas em cada escama é pequeno, não se pode descartar a possibilidade de que as diferenças encontradas sejam o resultado de uma das causas apontadas por Burton et al. (1995), Chavagnac e Jahn (1996) e Thöni (2003). Essas idades mostram coerência com os dados estruturais e microestruturais descritos por Silva (2003) que mostram o auge metamórfico em um estágio cedo - D2, portanto as idades obtidas referemse a um estágio anterior às falhas de empurrão, que justapõem as escamas de diferentes condições de metamórficas.

Outra possibilidade de interpretação destas idades de metamorfismo é que representem diferentes idades de extrusão tectônica de rochas relacionadas a um único evento metamórfico. Neste caso os empurrões responsáveis pela formação das escamas fariam cada escama cruzar a temperatura de fechamento em diferentes momentos, quando registram a idade de fechamento do sistema $\mathrm{Sm} / \mathrm{Nd}$ na granada. Tendo em vista que estudos de geotermometria indicaram temperaturas de metamorfismo de $340^{\circ} \mathrm{C}, 470-520^{\circ} \mathrm{C}$, $520-590^{\circ} \mathrm{C}$, respectivamente para as escamas inferior, intermediária, e superior (Silva, 2003). Estas temperaturas dos auges metamórficos são iguais ou inferiores às temperaturas de fechamento do sistema $\mathrm{Sm} / \mathrm{Nd}$ em granada $\left(600^{\circ} \mathrm{C}\right)$, o que torna esta hipótese pouco provável. Adicionalmente, a temperatura de metamorfismo que é progressivamente mais baixa nas escamas mais novas é coerente com o esperado para o modelo de auge metamórfico diacrônico, e não necessariamente para o modelo controlado pela temperatura de fechamento $\mathrm{Sm} / \mathrm{Nd}$ em granada.

As idades de metamorfismo obtidas para as amostras G83 e T250 são problemáticas, visto que possuem idades bem abaixo do esperado. Supõe-se que as idades isocrônicas sejam influenciadas pela presença de inclusões. Análises petrográficas realizadas nas amostras analisadas (ver Tabela 1) mostram que as granadas das amostras G83 e T250 apresentam inclusões de quartzo, plagioclásio, ilmenita, turmalina, e também de epidoto. Segundo Thöni (2003) o efeito de inclusões de epidoto, que é rico em terras raras leves, na sistemática $\mathrm{Sm} / \mathrm{Nd}$ e nas idades de granada é complexo. Depende da concentração dos elementos, da razão 
$\mathrm{Sm} / \mathrm{Nd}$ e da composição isotópica de $\mathrm{Nd}$, tanto das inclusões quanto na granada. Mas, em qualquer caso o desequilíbrio isotópico de $\mathrm{Nd}$ entre granada e inclusões resultará em idades espúrias, provocando distorções na isócrona "verdadeira" da granada, podendo resultar tanto em idades muito mais jovens ou muito mais velhas. No caso das amostras estudadas supomos que as idades isocrônicas foram distorcidas para baixo, ocasionando em idades mais novas que as esperadas para isócrona "verdadeira”.

\section{AGRADECIMENTOS}

Este trabalho é parte da tese de doutorado do primeiro autor que agradece à FAPESP pela bolsa (Processo $\mathrm{N}^{\circ}$ 98/16429-4) e pelo financiamento do projeto de pesquisa (Processo No 01/08456-6). Agradecemos os colegas Wellington Damázio, Samuel Ferreira, George Luvizotto, Frederico Andrade, Amarildo Ruiz e Guilhermo Navarro, pela colaboração nos trabalhos de campo. A Ana Costa, Carlos Fernandes, Paulo Costa, João Matos e Ivaldo Trindade pela leitura das primeiras versões do manuscrito. Aos revisores pelas críticas e sugestões feitas ao trabalho.

\section{REFERÊNCIAS BIBLIOGRÁFICAS}

ARNDT, N. T.; GOLDSTEIN, S. L. Use and abuse of crustformation ages. Geology, v. 15, p. 893-895, 1987.

ARGLES, T. W.; PRINCE, C. I.; FOSTER, G. L.; VANCE, D. New garnets for old? Cautionary tales from young mountain belts. Earth Planet. Sci. Lett., v. 172, p. 301-309, 1999.

BRITO NEVES, B. B.; CORDANI, U. G. Tectonic evolution of South America during the Late Proterozoic. Precambrian Research, v. 53, p. 23-40, 1991.

BURTON, K. W.; KOHN, M. J.; COHEN, A. S.; O’NIONS, R. $\mathrm{K}$. The relative diffusion of $\mathrm{Pb}, \mathrm{Nd}, \mathrm{Sr}$ and $\mathrm{O}$ in garnet. Earth Planet. Sci. Lett., v. 133, p. 199-211, 1995.

CHAVAGNAC, V;; JAHN, B. Coesite-bearing eclogites from the Bixiling Complex, Dabie Mountains, China: Sm-Nd ages, geochemical characteristics and tectonic implications. Chemical Geology, v. 133 p. 29-51, 1996.

CORDANI , U. G.; SATO K. Crustal evolution of the South American Platform, based on Nd isotopic systematics on granitoid rocks. Episodes, v. 22, p. 167-173, 1999.

COSTA, A. C. D. Geologia e geocronologia Sm-Nd e U-Pb na região do lineamento Patos: limite entre os blocos crustais do domínio Rio Grande do Norte e da Zona trans- versal, Província Borborema. 2002. Tese (Doutorado) - Instituto de Geociências e Ciências Exatas, Universidade Estadual Paulista, Rio Claro, São Paulo.

DANTAS, E. L. Geocronologia U-Pb e Sm-Nd de terrenos Arqueanos e Paleoproterozóicos do Maciço Caldas Brandão, NE do Brasil. 1996. Tese (Doutorado) - Instituto de Geociências e Ciências Exatas, Universidade Estadual Paulista, Rio Claro, São Paulo.

DEPAOLO, D. J. Crustal growth and mantle evolution: inference form models of elements transport and $\mathrm{Nd}$ and $\mathrm{Sr}$ isotopes. Geochimica Cosmochimica Acta, v. 44, p. 1185-1196, 1980.

FETTER, A. H. U-Pb and Sm-Nd geochronological constraints on the crustal framework and geological history of Ceará State, NW Boroborema Province, NE Brazil: implications for the assembly of Gondwana. 1999. Doctoral Thesis - University of Kansas.

FISHEL, D. P.; PIMENTEL, M. M.; FUCK, R. A. Idade do metamorfismo de alto grau no complexo Anápolis-Itauçu, Goiás, determinada pelo método Sm-Nd. Revista Brasileira de Geociências, v. 28, p. 543-544, 1998.

HASUI, Y.; ALMEIDA, F. F. M. Geocronologia do centrooeste brasileiro. Boletim da Sociedade Brasileira de Geologia, v. 19, p. 5-26, 1970.

HUMPHRIES, F. J.; CLIFF, R. A. Sm-Nd dating and cooling history of Scourian granulites, Sutherland. Nature, v. 295, p. 515-517, 1982.

LUGMAIR, G. W.; MARTI, K. Lunar initial ${ }^{143} \mathrm{Nd} /{ }^{144} \mathrm{Nd}$ : differencial evolution of the lunar crust and mantle. Earth Plan Sci. Lett., v. 39, p. 349-357, 1978.

McLENNAN, S. M.; HEMMING, S. R.; TAYLOR, S. R.; ERIKSON, K. A. Early Proterozoic crustal evolution: geochemical and $\mathrm{Nd}-\mathrm{Pb}$ isotopic evidence from metasedimentary rocks, southwestern North America. Geochimica et Cosmochimica Acta, v. 59, p. 1153-1177, 1995.

MEZGER, K.; ESSENE, E. J.; HALLIDAY, A. N. Closure temperatures of the Sm- Nd system in metamorphic garnets. Earth Planet. Sci. Lett., v. 113, p. 397-409, 1992.

PIMENTEL, M. M.; FUCK, R. A. Neoproterozoic crustal accretion in central Brazil. Geology, v. 20, p. 375-379. 1992.

PIMENTEL, M. M.; FUCK, R. A.; JUNGES, S. New Sm-Nd 
isotopic constraints for the age of metamorphic events in the Neoproterozoic Brasilia Belt, central Brazil. In: INTERNATIONAL CONFERENCE ON BASEMENT TECTONICS, 14., 1998. Ouro Preto. Anais...Ouro Preto: 1998. p. 50-52.

PIMENTEL, M. M.; FUCK, R. A.; FISCHEL, D. P. Estudo isotópico Sm-Nd regional da porção central da Faixa Brasília, Goiás: implicações para idade e origem dos granulitos do complexo Anápolis-Itauçu e rochas metassedimentares do Grupo Araxá. Revista Brasileira de Geociências, v. 29, p. 271-276, 1999.

PIMENTEL, M. M.; DARDENNE, M.A.; FUCK, R.A.; VIANA, M. G; JUNGES, S. L.; FISCHEL, D. P.; SEER, H. J.; DANTAS, E. $\mathrm{L}$. Nd isotopes and the provenance of detrital sediments of the Neoproterozoic Brasília Belt, central Brazil. Journal of South American Earth Science, v. 14, p. 571-585, 2001.

SATO, K.; TASSINARI, C. G.; KAWASHITA, K.; PETRONILHO, L. O método geocronológico Sm-Nd no IG/ USP e suas aplicações. Anais da Academia Brasileira de Ciências, v. 67, p. 313-336, 1995.

SEER, H. J. Evolução tectônica dos grupos Araxá, Ibiá e Canastra na Sinforma de Araxá, Araxá, Minas Gerais. 1999. Tese (Doutorado) - Instituto de Geociências, Universidade de Brasília, Brasília, DF.

SEER, H. J.; BROD, J. A.; FUCK, R. A.; PIMENTEL, M. M.; BOAVENTURA, G. R.; DARDENNE, M. A. Grupo Araxá em sua área tipo: um fragmento de crosta oceânica Neoproterozóica na Faixa de Dobramentos Brasília. Revista Brasileira de Geociências, v. 31, p. 385-396, 2001.

SILVA, C.H. 2003. Evolução Geológica da Faixa Brasília na Região de Tapira Sudoeste de Minas Gerais. Tese (Doutorado) - Instituto de Geociências e Ciências Exatas, Universidade Estadual Paulista, Rio Claro, São Paulo.

SILVA, C. H.; SIMÕES, L. S. A. Relação entre o crescimento de porfiroblastos e o desenvolvimento de foliações, exemplo das rochas da Faixa Brasília, na região de Tapira, SW de Minas Gerais. In: SIMPÓSIO NACIONAL DE ESTUDOS TECTÔNICOS, 10., 2005. Anais... Curitiba: SBG 2005. p. 493-496.

SILVA, C. H.; SIMÕES, L. S. A.; DAMÁSIO, W. L.; FERREIRA, S. M.; LUVIZOTTO, G. L. Geologia do Grupo Canastra em sua localidade-tipo e implicações na tectonoestratigrafia do segmento setentrional da Faixa Brasília. In: CONGRESSOBRASILEIRODE GEOLOGIA, 12., 2004.Araxá. Anais ... Araxá: SBG, 2004. p. 255.
TAYLOR, S. R.; McLENNAN S. M. The Continental Crust: its composition and evolution. Oxford: Blackwell, 1985. 312 p.

THÖNI, M. Erratum Sm-Nd isotope systematics in garnet from different lithologies (Eastern Alps): age results, and an evaluation of potential problems for garnet $\mathrm{Sm}-\mathrm{Nd}$ chronometry. Chemical Geology, v. 194, p. 353-379, 2003.

THÖNI, M.; JAGOUTZ, E. Some new aspects of dating eclogites in orogenic belts: $\mathrm{Sm}-\mathrm{Nd}, \mathrm{Rb}-\mathrm{Sr}$, and $\mathrm{Pb}-\mathrm{Pb}$ isotopic results from the Austroalpine Saualpe and Koralpe type-locality (Carinthia/ Styria, southeastern Austria). Geochim. Cosmochim. Acta, v. 56, p. 347-368, 1992.

VALERIANO, C. M. Evolução tectônica da extremidade meridional da Faixa Brasília, região da Represa de Furnas, Sudoeste de Minas Gerais. 1992.Tese (Doutorado) - Instituto de Geociências, Universidade de São Paulo, São Paulo.

VALERIANO, C. M. A Faixa Brasília meridional com ênfase no segmento da Represa de Furnas: Estado atual do conhecimento e modelos de evolução tectônica. 1999. Tese (Livre Docência) - Universidade Estadual do Rio de Janeiro, Rio de Janeiro.

VALERIANO, C. M.; SIMÕES, L. S. A.; TEIXEIRA, W.; HEILBRON, M. Southern Brasilia belt (SE Brazil): tectonic discontinuities, K-Ar data and evolution during the Neoproterozoic Brasiliano orogeny. Revista Brasileira de Geociências, v. 30, p. 295-299, 2000.

VALERIANO, C. M.; DARDENNE, M. A.; FONSECA, M. A.; SIMÕES, L. S. A.; SEER, H. J. A evolução tectônica da Faixa Brasília. In: MANTESSO NETO, V.; BARTORELLI, A.; CARNEIRO, C. D. R.; BRITO NEVES, B. B. (Org.). Geologia do Continente Sul-Americano: evolução da obra de Fernando Flávio Marques de Almeida. São Paulo: BECA, 2004. p. 575-592.

VALERIANO, C. M.; MACHADO, N.; SIMONETTI, A.; VALLADARES, C. S.; SEER, H. J.; SIMÕES, L. S. A. U-Pb Geochronology of the southern Brasília Belt (SE Brazil): sedimentary provenance, Neoproterozoic orogeny and assembly of West-Gondwana. Precambrian Research, v. 130, p. 27-55, 2004b.

VANCE, D.; HARRIS, N. Timing of prograde metamorphism in the Zanskar Himalaya. Geology, v. 27, p. 395-398, 1999. 